\title{
I came in with a cough and went out with an oedipal complex and castration anxiety (or what Balint work is not!)
}

\begin{abstract}
'The Balint doctor is seen as taking a firm grip of a patient with tedious physical symptoms and applying a specialised technique of psychiatric enquiry to elicit a psychological, preferably sexual, diagnosis. The correct interpretation is then expected to produce an instant cure.'
\end{abstract}

This amusing caricature, in Elder and Samuel's While I'm here Doctor, ${ }^{1}$ has come to typify the response of many to Balint's work. Although the readers of this Journal may have a more informed response, there is undoubtedly a risk that Balint's work will be maligned, marginalised, or even worse, forgotten, by new generations of doctors.

In this article, and the succeeding one in the November issue, I will discuss Balint's ideas in both their historical context and their relevance today.

It is the fate of the modern GP to consider him or herself over-worked, inadequately rewarded and under appreciated. However, the 1950 account of a visiting Australian, Joseph Collings, makes contemporary general practice seem a cakewalk.

$\mathrm{He}$ described his reception at a large practice in a densely populated area:

'I was made welcome "to see the procession", given a seat and invited to "stay as long as I liked". I was told, not without pride, that "we have seen 500 already today"; and I have no reason to doubt it. During my stay of an hour and a quarter about 120 more patients came in. They were "seen" by three different doctors, who replaced one another with almost bewildering rapidity. No pretence was made at real examination of any of these patients. An occasional temperature or pulserate was taken; four or five times a stethoscope was applied to a point somewhere below the thyroid gland

\author{
and some such utterance made as \\ "ah, a bit chesty"."
}

He concluded that general practice was in a parlous state and that there was ' $a$ failure to define general practice, and to establish and maintain standards'; it is against this backdrop that the Royal College of General Practitioners was founded in a bid to raise standards in training, practice and research.

The work of Michael Balint is all the more remarkable for having been born in such inimical circumstances. His own life was equally tumultuous. Born to a Jewish GP as 'Mihály Maurice Bergmann', he converted to Christianity, and changed his name against his father's wishes to 'Bálint Mihály'. He was forced out of his home in Hungary in the 1930s by the prevailing political conditions and emigrated to Manchester, where he met his third wifeto-be, Enid.

Together they ran seminars for GPs at Tavistock Square in London. The group of doctors met on a regular basis and brought difficult cases for discussion. The Balints' psychoanalytical background allowed them to bring a novel perspective to the group.

From these seminars, Balint wrote his seminal work The Doctor, his Patient and the Illness, which was published in $1957 .^{3}$

General practice provides the ideal arena in which to study the doctor-patient relationship as Balint did. It is very different from many hospital-based specialties and the relationship between GPs and their patients; patients may consult their GPs repeatedly, they can seek consultations on demand, and the areas about which they may consult know no bounds. He went as far as to suggest that general practice provides the only arena for such study:

'... research into the pathology and therapy of complaints of "psychological origin", that is, of the whole person, cannot, in my opinion be carried out by specialists, but only by general practitioners'. ${ }^{3}$

It was Balint who coined the concept of the 'doctor as a drug'. He recognised that in consultations with patients we may have a profound therapeutic effect, not by virtue of any pharmacological exhibition, but by our interaction with patients as fellow human beings. Like any drug however, there are side effects, although many of these may not be noted, by patient or doctor. The drug 'doctor' may therefore be helpful, harmful, or ineffectual.

Everything that is done by the doctor may affect the outcome of events. Even those things which many doctors do with little aforethought, such as examining a patient, may have a great influence on the patient's psyche, and affect their response to future illness.

Balint argues powerfully that by failing to consider psychological aspects of illness as having equal import to physical aspects of illness we run the risk of missing the 'pathology of the whole person', making a superficial or exclusively physical diagnosis, and failing to consider the patient's illness context.

GPs do not, on the whole, have any special training in dealing with psychological problems. Furthermore, despite more than 50 years having passed since Balint's work, there remains a difficulty in finding appropriate terminology to discuss the problems that most patients present with, for which the frank psychiatric terms such as 'depression' or 'anxiety' may be too blunt, or merely gloss over a complicated substratum.

The response to a patient's 'offers' in the consulting room may be one of the most important aspects of a GP's work. Often there is a 'request for a name for the 
illness'. Balint was all too aware of the importance of learned behaviour, suggesting 'neurotic tradition' as a descriptor of the escutcheon of psychopathology found in many families.

Having heard the patient's story, Balint observed that we often practice 'elimination by appropriate physical examination' without considering the effect of physical examination on the patient. Indeed sometimes there is danger in finding a physical sign!

Having reached a diagnosis, or perhaps having failed to arrive at one, advice and reassurance are often dispensed with alacrity. Yet Balint cautions against this too:

\section{'Never advise or reassure a patient before you have found out what the real problem is', noting that 'neurotics are hardly ever reassured, whilst those with physical illness may be. ${ }^{3}$}

Balint also had much to say about the relationship between GPs and consultants, perhaps as much a source of discomfiture today as it was in the 1950s. He concluded that GPs often failed to state their desiderata in letters to consultants, and that consultants 'instead of stating squarely and sincerely that they found no illness belonging to their special field which would account for the patient's complaints' offered 'futile pseudo-psychiatric advice'. ${ }^{3}$

There were a number of factors accounting for this unease: a preference for the diagnosis of physical rather than psychological illness; a shedding of responsibility by all three parties (GP, consultant and patient) leading to an institutional collusion of anonymity; perpetuation of the teacher-pupil relationship beyond what is realistic; lack of sufficient understanding of the patient's regressive tendencies in such circumstances; and the unhelpfulness of many specialists' reports.
Back in the consulting room, he urged GPs to take considered risks. Through leaps and bounds the doctor-patient relationship may be taken to a higher level, leaving behind the sterile, conservative general practice of the uninspired. Even so-called 'heartsinks' become sources of endless fascination, when one asks what it is that makes them worthy of the label.

The relationship is a manifold one: the patient that does not wish to discuss their marital strife on one day, is not prevented from seeking their GP's advice about a minor skin complaint. While some days the consultation may founder on the rocks in some areas, it will leap upwards in others.

Balint does not call for interpretation, nor playing 'the detective'. No special knowledge of psychological theory is required, only a willing ear and keen attention, while allowing patients to use their doctor as they would any other drug. GPs, wittingly or not, offer the possibility of a therapeutic relationship with their patients. We can understand our patients better by studying those relationships, which are at the heart of every consultation.

\section{Dan Edgcumbe}

\section{REFERENCES}

1. Elder A, Oliver S. While I'm here, doctor. London: Tavistock, 1987

2. Collings IS. General practice in England today, a reconnaissance. Lancet 1950; 25 March: 555-585.

3. Balint M. The doctor, his patient and the illness. 2nd edn. Edinburgh: Churchill Livingstone, 1963.

\section{Suggested Reading}

Balint E. The doctor, the patient and the group: Balint revisited. London: Routledge, 1993.

Balint E, Norell JS. Six minutes for the patient: interactions in general practice. London: Tavistock; 1973.

DOI: 10.3399/bjgp10X532512 